\title{
An infrared spectrophotometric method of estimating polyethylene glycol 4000
}

\author{
MARGARET W. DAVIES AND R. SHIELDS \\ From the Surgical Unit, Royal Infirmary, Cardiff
}

In studies of intestinal absorption non-absorbed markers are used to indicate changes in volume of the contents of the bowel. Polyethylene glycol 4000 (PEG 4000), a popular marker, has been shown to fulfil the criteria of a volume indicator (Hydén, 1956b; Jacobson, Bondy, Broitman, and Fordtran, 1963; Maddrey, Serebro, Marcus, and Iber, 1967; Shields, Harris, and Davies, 1968).

The concentration of PEG 4000 in biological fluids is usually determined by the turbidimetric method of Hydén (1956a) or one of its modifications (Lundh, 1958), both of which are based on the development of a PEG-TCA-Ba complex when PEG is exposed to trichloracetic acid (TCA) in the presence of barium ions. However, these methods are not entirely satisfactory (Malawer and Powell, 1967) and have the additional disadvantages of being tedious and time-consuming and requiring a considerable amount of glassware.

This paper describes a technique for the estimation of PEG 4000 by infrared spectrophotometry and compares its accuracy and precision with those of the turbidimetric methods (Hydén, 1956a; Lundh, 1958).

\section{PRINCIPLE}

Polyethylene glycol 4000, whose mean molecular weight is approximately 3,500 , is a condensation polymer of ethylene oxide and water, represented by the formula, $\mathrm{HOCH}_{2}\left(\mathrm{CH}_{2}-\mathrm{O}-\mathrm{CH}_{2}\right)_{n} \mathrm{CH}_{2} \mathrm{OH}$ ( $n$ ranging from 70 to 85).

From the observations of the infrared spectra of a number of compounds having a common group of atoms, it is found that, regardless of the rest of the molecule, this common group absorbs over a narrow range of frequencies, called the group frequency. In alkyl acetals, the $\mathrm{CH}_{2}$ group adjacent to the oxygen atom appears to have a characteristic frequency near $2,825 \mathrm{~cm}^{-1}$ (Brugel and Oster, 1956). Levins and Ikeda (1965) found one absorption band of PEG 1,000 to be approximately at this wave number. At a frequency of approximately $2,880 \mathrm{~cm}^{-1}$, the infrared absorption of PEG 4000 is directly proportional to its concentration.

It is not possible directly to measure the infrared absorption of an aqueous solution at $2,880 \mathrm{~cm}^{-1}$, because water absorbs very strongly at this wave number. However, carbon tetrachloride and acetone, in either of which PEG 4000 dissolves rapidly at $50^{\circ} \mathrm{C}$, do not absorb at this wave number and so can be used as a solvent. In the infrared spectrophotometric method, carbon tetrachloride and the sample containing PEG 4000 are mixed at $50^{\circ} \mathrm{C}$.

\section{APPARATUS}

A Perkin-Elmer infrared spectrophotometer (model 257) and two Perkin-Elmer sealed cells, type 281-2695, with Tefion spacers and Infrasil (fused silica) windows (a path length of $0.2 \mathrm{~mm}$ were used).

Glass bottles, of $10 \mathrm{ml}$ capacity, with airtight polythene caps are required, and two Eppendorf Marburg micropipettes $(0.1$ and $0.2 \mathrm{ml}$ capacity) and a hot plate, electrically maintained at $50^{\circ} \mathrm{C}$.

\section{REAGENTS}

CARBON TETRACHLORIDE (analytical grade)

POLYETHYLENE GLYCOL 4000 (Koch-Light Laboratories Ltd)

MODIFIED TYRODE'S SOLUTION (Code and McIntire, 1956). This solution is the one most frequently used in this laboratory for studies of intestinal absorption.

\section{PROCEDURE}

STANDARD SOLUTIONS Polyethylene glycol 4000 is dissolved in modified Tyrode's solution to give concentrations of 0.2 to $1.6 \mathrm{~g}$ in $100 \mathrm{ml}$ solution, at intervals of $0.2 \mathrm{~g} \%$. The blank is modified Tyrode's solution.

SAMPLE A $0.1 \mathrm{ml}$ sample, containing approximately 1 mg PEG 4000, is pipetted into a glass bottle and evaporated to dryness on the hot plate. Then $0.2 \mathrm{ml}$ carbon tetrachloride is added. The bottle is immediately capped and replaced on the hot plate for five to 10 minutes. The solution is allowed to cool to room temperature, and its infrared absorption is measured at $2,880 \mathrm{~cm}^{-1}$, using carbon tetrachloride as a blank. All estimations are carried out in duplicate. The same procedure is followed for the standard solutions of PEG 4000 and the blank Tyrode's solution. The concentration of PEG $\mathbf{4 0 0 0}$ 
in the sample is calculated from the regression of the absorption on the concentration of the standard solutions.

\section{RELIABILITY OF METHOD}

The accuracy and precision of the infrared spectrophotometric method were compared to those of the turbidometric methods (Hydén, 1956a; Lundh, 1958) by performing recovery experiments. Polyethylene glycol 4000 was dissolved in human intestinal perfusate obtained during studies of colonic absorption (Shields, 1966). Thirty-six solutions were prepared to give a range of concentration from 0.45 to $1.5 \mathrm{~g} \%(\mathrm{w} / \mathrm{v})$. With each method and using the same standard solutions, the concentration of PEG 4000 was estimated in duplicate and the mean recovery calculated.

A Unicam 500 spectrophotometer with glass cuvettes of $1 \mathrm{~cm}$ pathlength was used in the turbidimetric methods.

\section{RESULTS}

CALIBRATION CURVES Over the range $0-1.6 \mathrm{~g} \%$, the relationship between absorption and concentration of PEG 4000 most closely approximated a straight line with the infrared spectrophotometric technique (Fig. 1).

ACCURACY AND PRECISION The mean recovery of PEG $\mathbf{4 0 0 0}$ from intestinal perfusate estimated by the three methods is shown in Table I. With the infrared spectrophotometric method, PEG 4000 can be completely recovered from intestinal perfusate whereas the turbidimetric methods will systematically underestimate the concentration of PEG 4000. The coefficients of variation of the difference between duplicate estimations were $3 \cdot 1 \%$ (infrared spectrophotometric method), $1.7 \%$ (Hydén method), and $2.5 \%$ (Lundh modification). Analysis of variance of the difference between duplicates showed that the Hydén turbidimetric method was the most precise and the infrared spectrophotometric method, the least precise $(F=3.29 ; \mathrm{P}<0.05)$.

\section{DISCUSSION}

The recovery of PEG 4000 from intestinal perfusate was complete using the infrared spectrophotometric method. With the turbidimetric techniques no
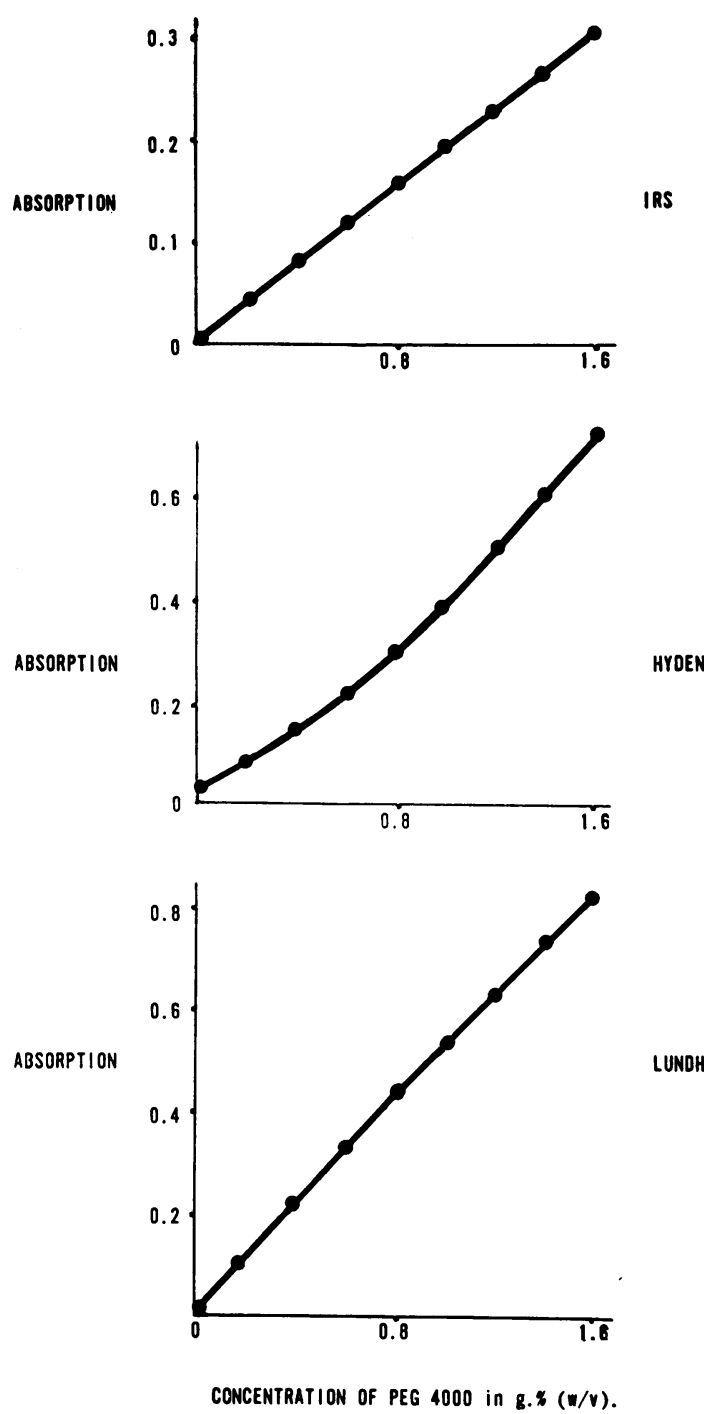

FIG. 1. The relationship between absorption and concentration of PEG 4000 using the infrared spectrophotometric (IRS) method, and the turbidimetric methods of Hydén and Lundh.

TABLE I

RECOVERY OF PEG 4000 FROM INTESTINAL PERFUSATE ${ }^{1}$

Infrared Spectrophotometric Method

$99.80 \pm 1.48$

$0.5>\mathrm{P}>0.4$
Hydén (1956) Method

$99 \cdot 14 \pm 1 \cdot 57$

$\mathbf{P}<0.01$
Lundh (1958) Method

$98.06 \pm 2.50$

$\mathbf{P}<0.001$

${ }^{1}$ Thirty-six solutions, ranging from 0.45 to $1.5 \mathrm{~g} \% \mathrm{w} / \mathrm{v}$, were estimated in duplicate. 
such complete recovery was attained. Although the infrared spectrophotometric method is less precise than the turbidimetric methods, accuracy is more desirable than precision in studies of intestinal absorption: indeed the latter can be increased by performing estimations in duplicate (see standard deviations in Table I). Also, the time taken to determine PEG 4000 by the infrared spectrophotometric technique is two-thirds of that required by the turbidimetric method, and only one-quarter of the amount of glassware is needed. Finally. because direct correlation between absorption and concentration of PEG $\mathbf{4 0 0 0}$ over the entire range was demonstrated with infrared spectrophotometric technique, fewer standard solutions of PEG $\mathbf{4 0 0 0}$ are necessary for routine analysis than with either of the turbidimetric techniques.

Our results with the turbidimetric methods compare favourably with those previously reported (Hydén, 1956a; Lundh, 1958; Jacobson et al, 1963).

\section{SUMMARY}

A method for the determination of PEG 4000 in intestinal perfusate is described, using infrared spectrophotometry. The absorption of PEG 4000 is measured at $2,880 \mathrm{~cm}^{-1}$, using carbon tetrachloride as the solvent after evaporation of the sample. The method is more accurate than existing turbidimetric methods. In addition, less time and glassware are required.
We are grateful to Professor A. P. M. Forrest for his interest and encouragement and to $\mathrm{Mr} \mathrm{J}$. James of Perkin-Elmer Limited for technical advice.

This work was supported by a grant from the Medical Research Council.

\section{REFERENCES}

Brugel, W., and Oster, A. (1956). Quoted by Bellamy, L. J. (1964). The Infra-red Spectra of Complex Molecules, p. 117. Methuen, London.

Code, G. F., and McIntire, E. C. (1956). Quantitative determination of histamine. Meth. biochem. Anal., 3, 49-95.

Hydén, S. (1956a). A turbidimetric method for the determination of higher polyethylene glycols in biological materials. K. LantbrHögsk. Annlr., 22, 139-145.

- (1956b). The recovery of polyethylene glycol after passage through the digestive tract. Ibid., 22, 411-424.

Jacobson, E. D., Bondy, D. C., Broitman, S. A., and Fordtran, J. S. (1963). Validity of polyethylene glycol in estimating intestinal water volume. Gastroenterology, 44, 761-767.

Levins, J., and Ikeda, R. M. (1965). Direct potentiometric titration of polyethylene glycols and their derivatives with sodium tetraphenylboron. Analyt. Chem., 37, 671-675.

Lundh, G. (1958). Intestinal digestion and absorption after gastrectomy. Acta chir. scand., suppl. 231.

Maddrey, W. C., Serebro, H. A., Marcus, H., and Iber, F. L. (1967). Recovery, reproducibility, and usefulness of polyethylene glycol, iodine-labelled rose bengal, sulphobromophthalein, and indocyanine green as non-absorbable markers. Gut, 8, 169-171.

Malawer, S. J., and Powell, D. W. (1957). An improved turbidimetric analysis of polyethylene glycol utilizing an emulsifier. Gastroenterology, 53, 250-256.

Shields, R. (1966). Absorption and secretion of electrolytes and water by the human colon, with particular reference to benign adenoma and papilloma. Brit. J. Surg., 53, 893-897.

- Harris, J., and Davies, M. W. (1968). The suitability of polyethylene glycol as a dilution indicator in the human colon. Gastroenterology, 54, 331-333. 